\title{
Combination of enzymes and flow perfusion conditions improves osteogenic differentiation of bone marrow stromal cells cultured upon starch/poly(e-caprolactone) fiber meshes
}

\author{
Ana M. Martins, ${ }^{1,2,3}$ Anita Saraf, ${ }^{3}$ Rui A. Sousa, ${ }^{1,2}$ Catarina M. Alves, ${ }^{1,2}$ Antonios G. Mikos, ${ }^{3}$ \\ F. Kurtis Kasper, ${ }^{3}$ Rui L. Reis ${ }^{1,2}$ \\ 13B's Research Group-Biomaterials, Biodegradables and Biomimetics, University of Minho, Headquarters of the European \\ Institute of Excellence on Tissue Engineering and Regenerative Medicine, AvePark, Taipas 4806-909, Guimarães, Portugal \\ ${ }^{2}$ IBB_-Institute for Biotechnology and Bioengineering, PT Government Associated Laboratory, Guimarães, Portugal \\ ${ }^{3}$ Department of Bioengineering, Rice University, 6100 Main Street, Houston, Texas 77005-1892
}

Received 4 September 2009; revised 9 December 2009; accepted 13 January 2010

Published online 31 March 2010 in Wiley InterScience (www.interscience.wiley.com). DOI: 10.1002/jbm.a.32785

\begin{abstract}
Previous studies have shown that $\alpha$-amylase and lipase are capable of enhancing the degradation of fiber meshes blends of starch and poly( $\varepsilon$-caprolactone) (SPCL) under dynamic conditions, and consequently to promote the proliferation and osteogenic differentiation of bone marrow stromal cells (MSCs). This study investigated the effect of flow perfusion bioreactor culture in combination with enzymes on the osteogenic differentiation of MSCs. SPCL fiber meshes were seeded with MSCs and cultured with osteogenic medium supplemented with $\alpha$-amylase, lipase, or a combination of the two for 8 or 16 days using static or flow conditions. Lipase and its combination with $\alpha$-amylase enhanced cell proliferation after 16 days. In addition, the flow perfusion culture enhanced the infiltration of cells and facilitated greater distribution of extracellular matrix (ECM) throughout the scaffolds in the presence/absence of enzymes. A significant amount of calcium was detected after 16 days in all groups cultured in
\end{abstract}

flow conditions compared with static cultures. Nevertheless, when $\alpha$-amylase and lipase were included in the flow perfusion cultures, the calcium content was $379 \pm 30 \mu \mathrm{g} /$ scaffold after as few as 8 days. The highest calcium content (1271 \pm 32 $\mu \mathrm{g} / \mathrm{scaffold}$ ) was obtained for SPCL/cell constructs cultured for 16 days in the presence of lipase and flow. Furthermore, von Kossa staining and tetracycline fluorescence of histological sections demonstrated mineral deposition within the scaffolds for all groups cultured for 16 days under flow. However, all the data corroborate that lipase coupled with flow perfusion conditions improve the osteogenic differentiation of MSCs and enhance ECM mineralization. (c) 2010 Wiley Periodicals, Inc. J Biomed Mater Res Part A: 94A: 1061-1069, 2010.

Key Words: starch/poly(e-polycaprolactone) fiber meshes, $\alpha$-amylase, lipase, flow perfusion bioreactor, osteogenic differentiation

\section{INTRODUCTION}

An ideal scaffold for bone tissue engineering should be biodegradable and bioresorbable while being able to support the growth of new bone. The scaffold degradation rate should complement the growth rate of the new bone such that the scaffold degrades in time for the new bone to occupy the site of defect or injury. ${ }^{1}$ In the case of starch and poly( $\varepsilon$-caprolactone) (SPCL) scaffolds, ${ }^{2,3} \alpha$-amylase ${ }^{4-8}$ and lipase $\mathrm{e}^{5,9,10}$ have been shown to facilitate the enzymatic hydrolysis of the starch and PCL components of the scaffold, respectively. Additionally, studies have also shown pronounced degradation of SPCL biomaterials when lipase and $\alpha$-amylase were used together. ${ }^{5,6}$ Since these enzymes are naturally present in humans, lipase and $\alpha$-amylase were used in this study at human blood serum concentrations to simulate in vivo conditions. In vitro, these enzymes have previously induced the degradation of SPCL scaffolds under static as well as dynamic conditions, as is indicated by the enhanced porosity and pore size of the scaffolds. In addition, the presence of these enzymes in culture media has induced the proliferation of rat marrow stromal cells cultured on SPCL scaffolds.

In this study, we were interested in examining the osteogenic potential of $\alpha$-amylase and lipase when added to osteogenic culture media in flow perfusion culture of MSCs. The osteogenic differentiation of MSCs in vitro starts with a period of cellular proliferation, followed by extracellular matrix (ECM) deposition and maturation, and ultimately mineralization of the matrix. ${ }^{11,12}$ To induce osteogenic differentiation of MSCs, the culture medium is typically supplemented with osteogenic agents such as ascorbic acid, $\beta$-glycerophosphate, and dexamethasone. To further facilitate osteogenesis, growth factors such as BMP-2 and BMP-4 have been added to culture media. However, most studies do not take into account the effect of physiological enzymes on cellular differentiation and scaffold degradation; two events that are

Correspondence to: R. L. Reis; e-mail: rgreis@dep.uminho.pt

Contract grant sponsor: Portuguese Foundation for Science and Technology (FCT); contract grant number: SFRH/BPD/26763/2006

Contract grant sponsor: European NoE EXPERTISSUES; contract grant number: NMP3-CT-2004-500283 
integral to designing successful strategies for bone tissue engineering. For example, a previous study in our laboratory described that lipase positively influences osteoblastic differentiation of rat MSCs and enhances matrix mineralization under static conditions when added to osteogenic culture medium. Previous studies with SPCL fiber mesh scaffolds using flow perfusion bioreactors have shown that flow perfusion conditions enhanced osteoblastic differentiation of rat bone marrow stromal cells (MSCs) ${ }^{2,3}$ due to the improved mass transport to the scaffold interior ${ }^{13}$ and to the mechanical stimulation of cells caused by the fluid shear force within the scaffold. ${ }^{14}$

Because of previous promising results indicating the osteoblastic differentiation of MSCs in the presence of lipase under static conditions, it was hypothesized in this study that the addition of mechanical stimulation of MSCs via fluid flow in the bioreactor would enhance osteogenesis of MSCs in the presence of enzymes such as lipase and $\alpha$-amylase at physiological concentrations. Specifically, this study was designed to investigate the following: (1) The efficacy of $\alpha$ amylase and/or lipase enzymes as osteogenic supplements in culture media for osteogenic differentiation of rat bone marrow stromal cells and (2) the effect of lipase and $\alpha$-amylase at physiological concentrations, in combination with flow perfusion conditions, on the osteogenic differentiation of rat bone marrow stromal cells.

\section{MATERIALS AND METHODS}

\section{Scaffold preparation}

Blends of corn starch and poly( $\varepsilon$-caprolactone) (SPCL, 30/ $70 \%$ ) fiber mesh scaffolds were prepared by a fiber bonding technique 2,3 with a porosity of $60 \% \pm 3 \%$ and an average fiber diameter of $226 \pm 1 \mu \mathrm{m}$. The porosity and fiber diameter were determined using microcomputed tomography ( $\mu$-CT) as previously described. ${ }^{8}$ The average pore size was $339 \pm 31 \mu \mathrm{m}^{8}$ Scaffolds were die-punched into 8-mm diameter disks (thickness $=1-1.5 \mathrm{~mm}$ ). Further details on the scaffolds can be found elsewhere. ${ }^{2,3}$ Before cell seeding, scaffolds were sterilized by exposure to ethylene oxide gas for $14 \mathrm{~h}$. All chemical reagents were purchased from Sigma (St. Louis, MO), unless otherwise specified.

\section{Isolation, expansion, seeding, and culture of rat bone marrow stromal cells}

Rat bone marrow stromal cells (MSCs) were obtained from femura and tibiae of 41-44 day-old male Wistar rats (Charles River Laboratories) using the method described by Maniatopoulos et al. ${ }^{15}$ The harvested cells were cultured in a humidified atmosphere with $5 \% \mathrm{CO}_{2}$ at $37^{\circ} \mathrm{C}$ until they were confluent. Medium was changed at 1 and 3 days to remove the nonadherent cell population.

SPCL fiber mesh scaffolds were immersed in complete osteogenic medium [ $\alpha$-MEM supplemented with 10\% fetal bovine serum (FBS) from Cambrex/BioWhittaker (Walkersville, MD), $50 \mu \mathrm{g} / \mathrm{mL}$ gentamicin, $100 \mu \mathrm{g} / \mathrm{mL}$ ampicilin, 10 $\mathrm{m} M$ fungizone, $50 \mu \mathrm{g} / \mathrm{mL}$ L-ascorbic acid, $0.01 M \beta$-glycerophosphate, and $10^{-8} \mathrm{M}$ dexamethasone] overnight and were press fit into 8-mm diameter cassettes on the following day.
Cassettes were placed into 6-well plates. Each scaffold was seeded with 500,000 cells in $300 \mu \mathrm{L}$ of complete osteogenic medium as described previously. ${ }^{8}$ Cells were allowed to attach for $2 \mathrm{~h}$ before adding $10 \mathrm{~mL}$ of osteogenic medium to each well of the 6-well plate. After $24 \mathrm{~h}$ of attachment, the scaffolds were placed in new six-well plates (static culture condition) or in a flow perfusion bioreactor for 7 and 15 days with four different media conditions; specifically, complete osteogenic media (i) without enzymes, (ii) with $\alpha$ amylase $(150 \mathrm{U} / \mathrm{L}),{ }^{8,16}$ (iii) with lipase $(110 \mathrm{U} / \mathrm{L}),{ }^{8,17}$ or (iv) with $\alpha$-amylase and lipase in concentrations similar to those found in human blood serum $\left(150 \mathrm{U} / \mathrm{L}^{8,16}\right.$ and $110 \mathrm{U} / \mathrm{L}^{8,17}$ respectively).

The flow perfusion bioreactor is described in detailed elsewhere. ${ }^{13,18}$ Briefly, the flow perfusion bioreactor consists of six flow chambers within a block. Each flow chamber contains a cassette in which the scaffold is press-fit. Each cassette is sealed with two 0-rings to ensure no media leakage around the edge of the cassette. Gas-permeable silicon tubing connects each flow chamber with a peristaltic pump and a medium reservoir. Media were changed every 2-3 days. Each group consisted of $n=6$ samples. For these experiments, culture media were pumped continuously at the flow rate of $1 \mathrm{~mL} / \mathrm{min}$ each cell/scaffold construct and recirculate back to the reservoir.

At the end of each culture period, samples were removed from the cassettes and rinsed with phosphate buffered saline (PBS) solution. Three samples from each group were stored at $-20^{\circ} \mathrm{C}$ in $\mathrm{ddH}_{2} \mathrm{O}$ for biochemical analysis. The remaining samples were fixed with $2.5 \%$ glutaraldehyde for scanning electron microscopy (SEM) analysis or with $10 \%$ formalin solution for histological evaluation.

\section{DNA analysis}

The cells in the constructs were lysed by repeated freezethaw cycles in $d_{d} \mathrm{H}_{2} \mathrm{O}$. The DNA content of the lysates was quantified by using a DNA quantification kit (PicoGreen, Molecular Probes) and correlated to DNA from a known amount of rat marrow stromal cells. Frozen scaffolds were thawed at room temperature, sonicated for $10 \mathrm{~min}$, and vortexed to allow cellular DNA into solution. Buffer provided with the kit was diluted with $\mathrm{ddH}_{2} \mathrm{O}$ and placed in each well of a 96-well plate at $100 \mu \mathrm{L} /$ well. DNA standard solutions in $\mathrm{ddH}_{2} \mathrm{O}$ in concentrations from 0 to $6 \mu \mathrm{g} / \mathrm{mL}$ were prepared, and $50 \mu \mathrm{L}$ of standards/samples were added to each well of the 96-well plate. PicoGreen dye solutions were prepared according to the instructions of the manufacturer using reagents provided in the kit and added at $150 \mu \mathrm{L} /$ well. All these procedures were performed in triplicate. After 10 min of incubation in a dark room, the fluorescence at $545 \mathrm{~nm}$ was read on a plate reader (FLx800, Bio-Tek Instruments, Winooski, VT) to determine DNA concentrations per scaffold. A conversion factor of 2.7 pg DNA/cell was used to calculate cell number based on MSC standards.

\section{Alkaline phosphatase activity}

Alkaline phosphatase activity assays were performed on cell lysates using an established protocol. ${ }^{19}$ All samples were 
prepared in triplicate and compared against $p$-nitrophenol standards. The reaction was stopped by adding $100 \mu \mathrm{L}$ of $0.3 \mathrm{~N} \mathrm{NaOH}$. Absorbance was read at $405 \mathrm{~nm}$ on a plate reader (PowerWave $\times 340$; Bio-Tek, Winooski, VT) to determine the alkaline phosphatase activity per scaffold.

\section{Calcium deposition measurement}

Calcium content in the SPCL fiber mesh scaffolds was measured by using a Calcium Kit (Diagnostic Chemical Limited, Oxford, CT). After the ALP and DNA assays, a volume of $1 \mathrm{~N}$ acetic acid equal to the volume remaining in each well was added to each sample (final concentration of $0.5 \mathrm{~N}$ ), and the plate was placed on an orbital shaker overnight. A volume of $300 \mu \mathrm{L}$ of calcium assay reagent was added to $20 \mu \mathrm{L}$ of sample solution in triplicate in 96-well plates. To generate a standard curve, serial dilutions of $\mathrm{CaCl}_{2}$ were prepared (0$50 \mu \mathrm{g} / \mathrm{mL}$ ). Absorbance was read at $650 \mathrm{~nm}$ using a spectrophotometric plate reader $(\mathrm{FL} \times 800$, Bio-Tek Instruments, Winooski, VT). The calcium deposition in each scaffold is reported as $\mu \mathrm{Ca}^{2+}$.

\section{Histological and microscopic analysis}

After each time period, SPCL fiber mesh scaffolds were removed from the cassettes, washed twice in PBS, and fixed with $2.5 \%$ glutaraldehyde for $30 \mathrm{~min}$. Then, the scaffolds were washed with PBS and dehydrated in a graded series of ethanol, dried by hexamethyldisilazane, mounted on aluminum stages, sputter-coated with gold, and examined with an FEI Quanta 400 Environmental Scanning Electron Microscope (Hillsboro, OR). Scanning electron microscopy (SEM) and light microscopy were used to evaluate the morphological appearance and infiltration of the bone marrow stromal cells and deposited matrix. The samples for SEM observation were cut in half for analysis of both the top and bottom; additionally, cross sections were cut. The samples were sputter-coated with gold, examined and photographed with an FEI Quanta 400 Environmental Scanning Electron Microscope (Hillsboro, OR).

The remaining cultured samples were rinsed with PBS, fixed in $10 \%$ formalin solution, and embedded in HistoPrep freezing medium (Fisher Scientific, Pittsburgh, PA). Frozen sections of $\sim 10-15 \mu \mathrm{m}$ thickness were obtained using a cryostat (HM500, Microm, Walldorf, Germany) operating at $-23^{\circ} \mathrm{C}$ and mounted onto Superfrost Plus glass slides (Fisher Scientific, Pittsburgh, PA), then stained with hematoxylin and eosin for histological evaluation. For visualization of mineralized tissue, additional sections were exposed to $5 \%$ silver nitrate solution under UV for $25 \mathrm{~min}$ and counterstained with $0.5 \%$ safranin 0 solution. von Kossa stained sections were observed using a light microscope (Eclipse E600; Nikon, Melville, NY) and attached video camera (3CCD Color Video Camera DXC-950P; Sony, Park Ridge, NJ). Mineral deposition was also visualized in unstained sections under fluorescent light after adding tetracycline- $\mathrm{HCl}$ to the culture media at a final concentration of $10 \mu \mathrm{g} / \mathrm{mL}^{2,14}$ All the histological sections, except von Kossa stained sections, were visualized using an Olympus BX61 Motorized System
Microscope and attached video camera Olympus DP70 equipped with a fluorescence lamp.

\section{Statistics}

Results of DNA, ALP, and calcium assay are expressed as mean \pm standard deviation with $n=3$ for each group. Single factor analysis of variance (ANOVA) was used to determine statistical significance within a data set. If ANOVA detected a significant difference within the data set, Tukey's honestly significantly different (HSD) multiple comparison test was used to determine significant differences between groups and conditions. All tests were conducted with a confidence interval of $95 \%(p<0.05)$.

\section{RESULTS AND DISCUSSION DNA assay}

A significant improvement in cell number was generally observed in flow perfusion conditions when compared with static cultures (Fig. 1). SEM images (Figs. 2 and 3) and H\&E stained sections (Fig. 4) also confirm these results. The SPCL/cell constructs cultured without enzymes or with $\alpha$ amylase in flow perfusion conditions reached their peak cellularities at day 8, and after that point they demonstrated a significant decrease in the number of cells measured in each scaffold (Fig. 1), in agreement with previous experiments. ${ }^{2,3}$ In contrast, the DNA results showed an increase in cell numbers after 16 days for SPCL scaffolds cultured with lipase or with both enzymes. Scaffolds cultured in the presence of lipase or with both enzymes, under flow conditions after 16 days, had almost three and two times higher cellularity, respectively, when compared with SPCL/cell constructs cultured for 16 days under flow conditions without enzymes.

\section{Microscopic analysis}

Cross sections of all groups were visualized using SEM to evaluate cell morphology and infiltration and deposition of extracellular matrix. Culturing the constructs in a flow perfusion bioreactor enhanced the infiltration of MSCs for all groups (Fig. 3). Previous studies have also demonstrated

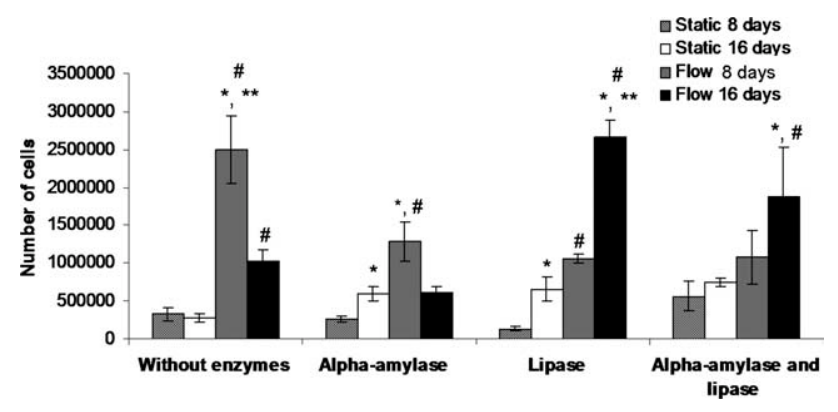

FIGURE 1. Cellularity of SPCL fiber meshes cultured in vitro without enzymes, with $\alpha$-amylase, lipase, $\alpha$-amylase, and lipase in static or flow perfusion conditions for 8 and 16 days. Results are expressed as means \pm standard deviation with $n=3$ for each bar. * Indicates a significant difference $(p<0.05)$ between 8 and 16 days; $* *$ indicates a significant difference $(p<0.05)$ between groups (with and without enzymes) in static or flow conditions; and ${ }^{\#}$ indicates a significant difference $(p<0.05)$ between flow and static conditions. 


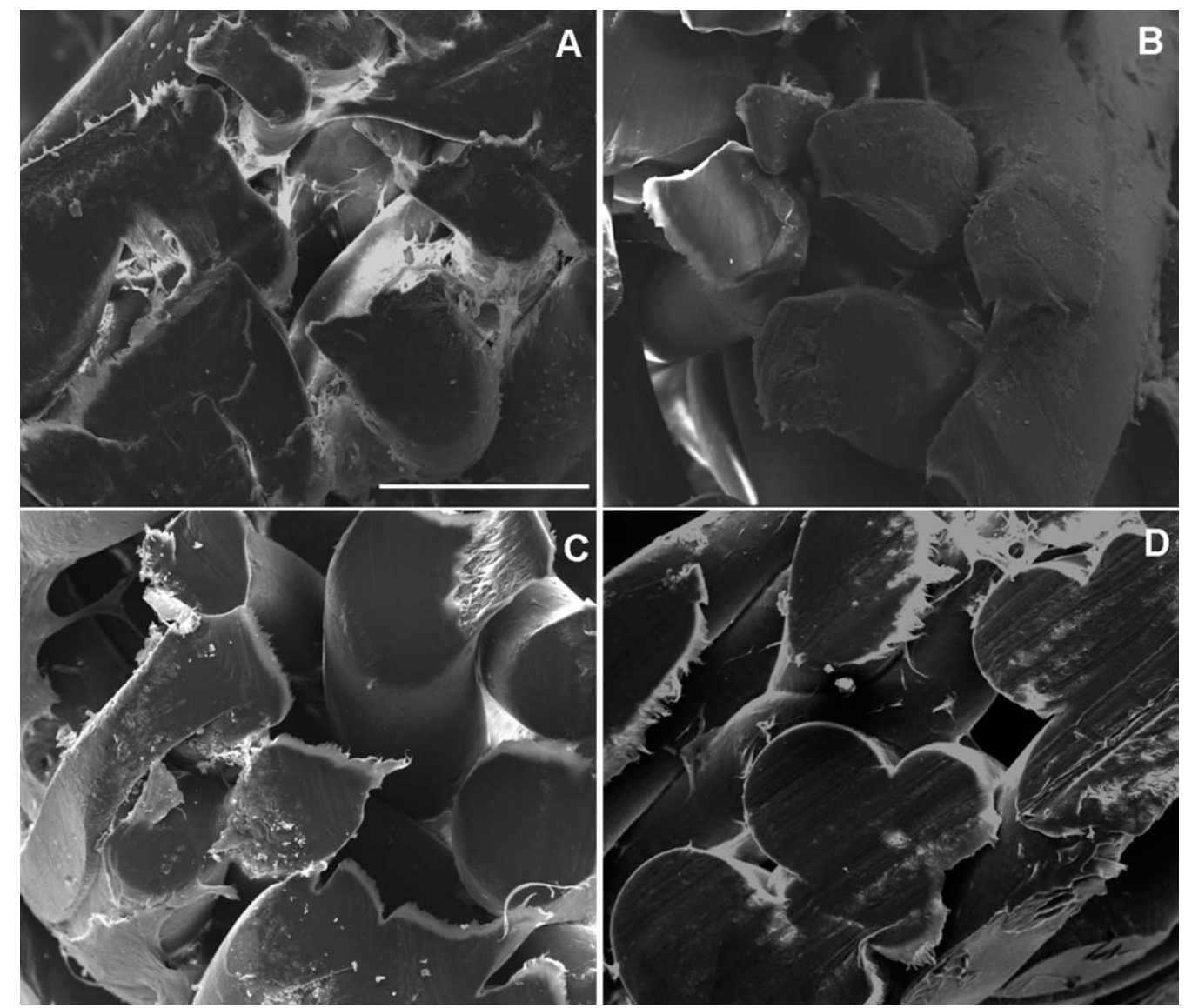

FIGURE 2. SEM images of the cross sections of SPCL fiber mesh scaffolds cultured without enzymes (A), with $\alpha$-amylase (B), with lipase (C), or with $\alpha$-amylase and lipase (D) in static conditions after 16 days. The scale bar is $400 \mu \mathrm{m}$ and applies to all images.

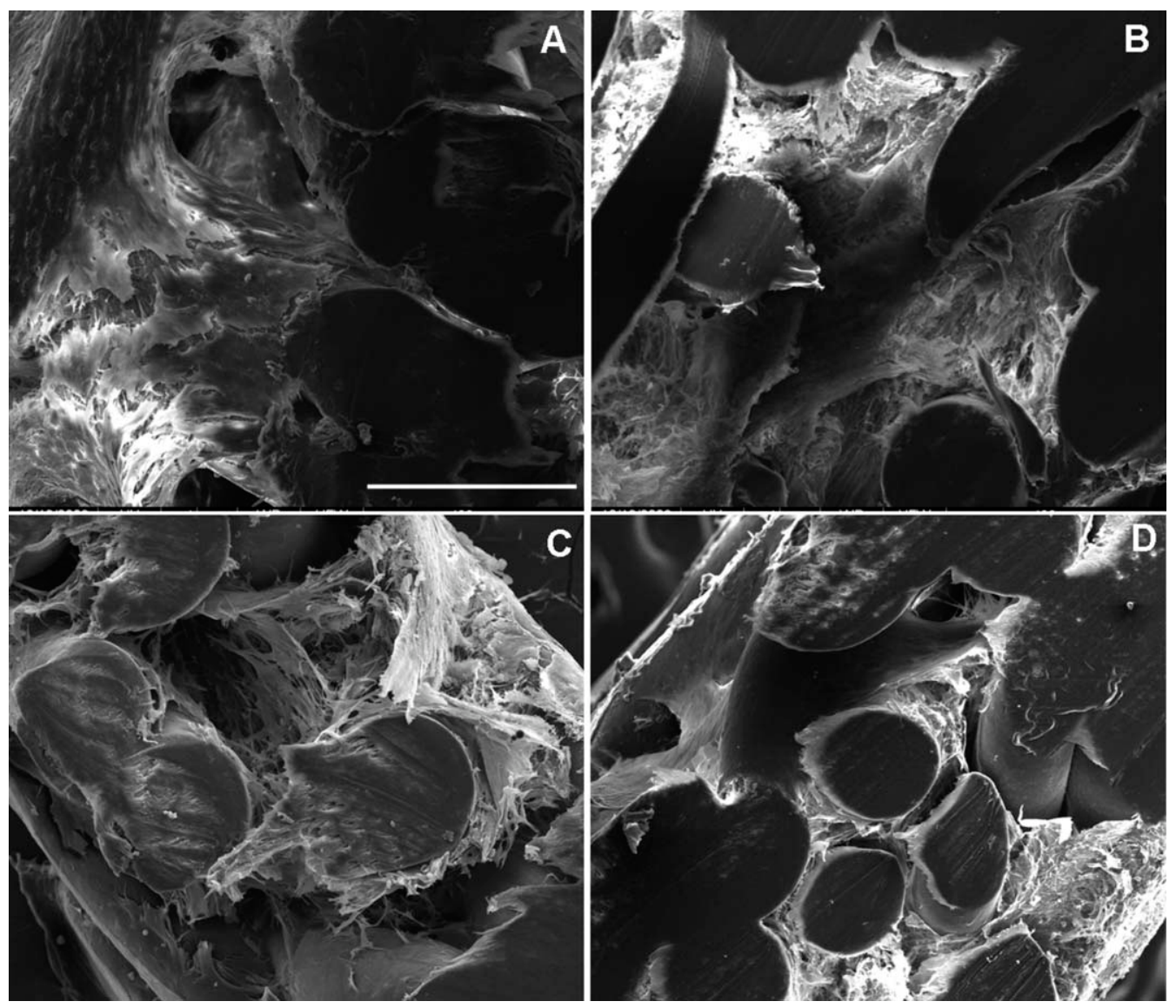

FIGURE 3. SEM images of the cross sections of SPCL fiber mesh scaffolds cultured without enzymes (A), with $\alpha$-amylase (B), with lipase (C), or with $\alpha$-amylase and lipase (D) in flow perfusion conditions after 16 days. The scale bar is $400 \mu \mathrm{m}$ and applies to all images. 

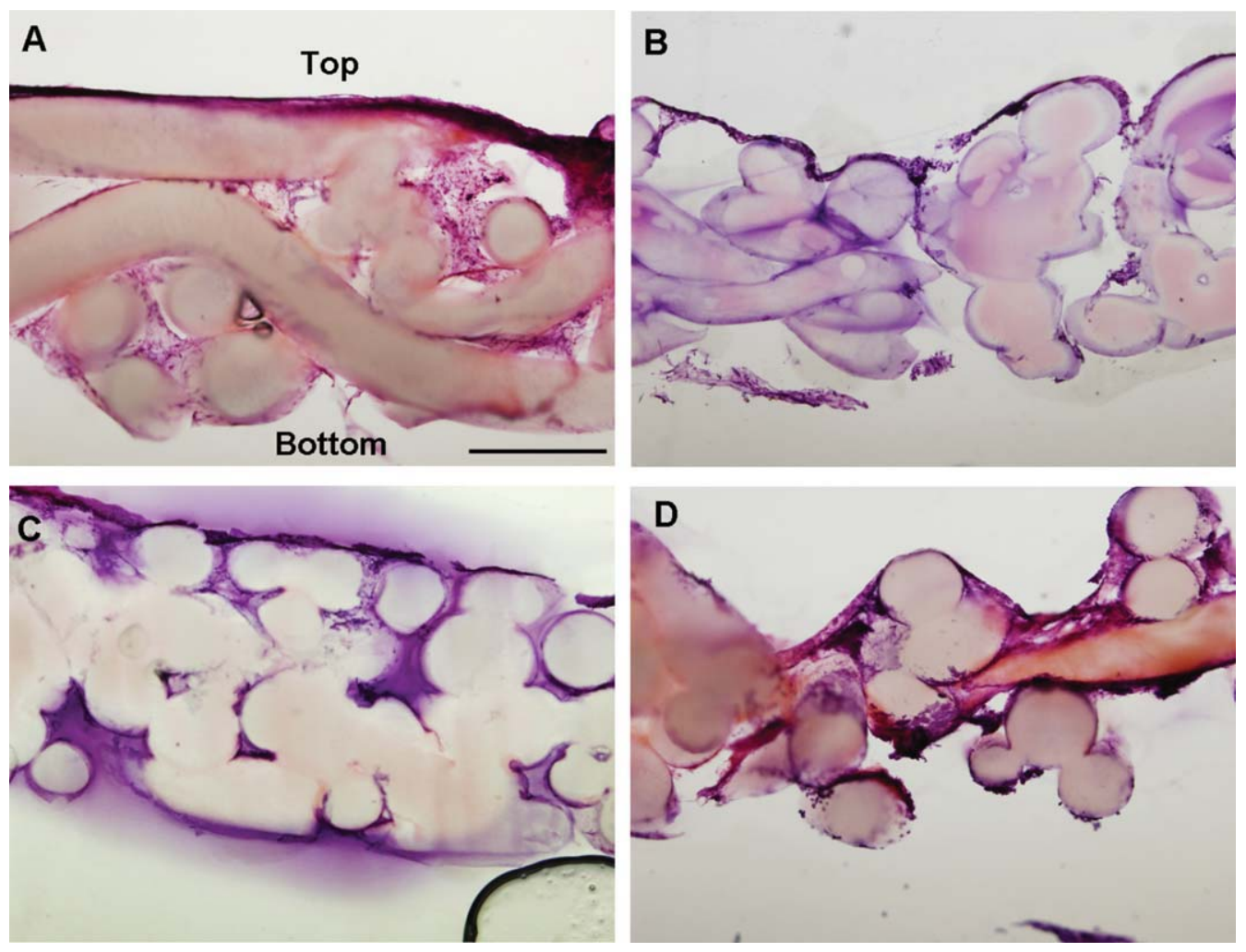

FIGURE 4. Representative histological cross sections of SPCL fiber mesh scaffolds cultured for 16 days in flow perfusion conditions without enzymes (A), with $\alpha$-amylase (B), with lipase (C), or with $\alpha$-amylase and lipase (D). The flow direction was from the top of the image through the scaffold to the bottom. Sections have been stained with hematoxylin and eosin and shown at $\times 4$ magnification. The scale bar corresponds to $500 \mu \mathrm{m}$ and applies to all images. [Color figure can be viewed in the online issue, which is available at www.interscience.wiley.com.]

that flow perfusion culture increased the distribution and infiltration of cells when compared with static culture..$^{2,20-22}$ This was further confirmed by histological evaluation of the scaffolds (Fig. 4). The cellular distribution observed in static, as well as in flow conditions, was not influenced by the presence of the enzymes. Cross-sectional images of all groups cultured under flow perfusion conditions revealed infiltration of cells through the bottom of the scaffolds and the presence of matrix between fibers deeper within the scaffolds (Fig. 3) when compared with constructs that were cultured statically (Fig. 2). Furthermore, SEM images indicated that the enzymes did not have a deleterious effect on the structure of SPCL fiber meshes, meaning that the constructs did not loose their structural integrity after 16 days, even when flow perfusion conditions and enzymes were used (Fig. 3). This was further confirmed with histological cross sections, which additionally showed that there were no observable differences between scaffolds cultured in flow conditions with respect to the distribution and infiltration of cells (Fig. 4).

\section{Alkaline phosphatase activity}

ALP is considered to be an early stage marker of osteogenic differentiation. ${ }^{12}$ Typically, a rise and fall of ALP activity is characteristic of osteoblastic differentiation. ${ }^{2,3}$ However, ALP can be expressed at high levels near the end of the proliferative period and during the period of extracellular matrix deposition and maturation. ${ }^{12}$ Such a trend is observed in Figure 5, where all groups cultured under flow conditions, with the exception of SPCL/cell constructs supplemented with both enzymes, had a significant increase of ALP activity at day 16. The highest peak of ALP activity was observed for SPCL/cell constructs cultured without enzymes in flow perfusion conditions. The ALP activity was normalized to reflect the ALP activity per cell. Results show significant

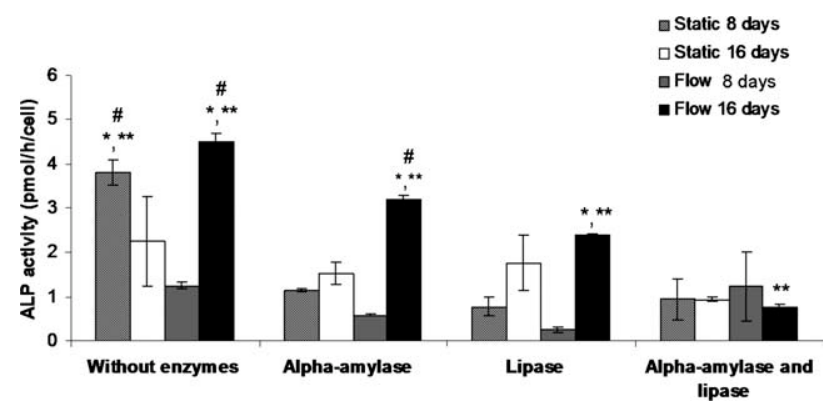

FIGURE 5. Alkaline phosphatase activity of rat bone marrow stromal cells cultured in vitro without enzymes, with $\alpha$-amylase, with lipase, or with $\alpha$-amylase and lipase upon SPCL fiber mesh scaffolds for up to 16 days in static and flow conditions. Results are expressed as means \pm standard deviation with $n=3$ for each bar. * Indicates a significant difference $(p<0.05)$ between 8 and 16 days; $* *$ indicates a significant difference $(p<0.05)$ between groups (with and without enzymes) in static or flow conditions; and \# indicates a significant difference $(p<0.05)$ between flow and static conditions. 


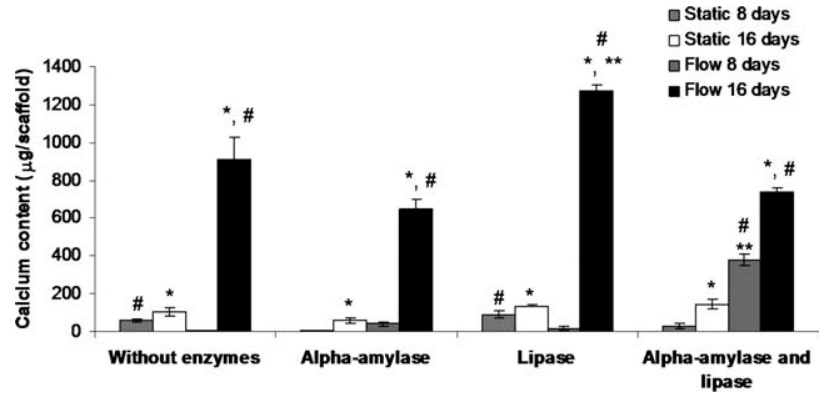

FIGURE 6. Calcium content of SPCL fiber mesh scaffolds cultured in vitro without enzymes, with $\alpha$-amylase, with lipase, or with $\alpha$-amylase and lipase in static and flow conditions for 8 and 16 days expressed as total calcium per scaffold. Results are expressed as means \pm standard deviation with $n=3$ for each bar. * Indicates a significant difference $(p<0.05)$ between 8 and 16 days; ${ }^{*}$ indicates a significant difference ( $p<0.05$ ) between groups (with and without enzymes) in static or flow conditions; and ${ }^{\#}$ indicates a significant difference ( $p<$ 0.05 ) between flow and static conditions.

differences between flow perfusion and static cultures for complete osteogenic media without enzymes, with $\alpha$-amylase, and with lipase. Flow significantly enhanced the ALP activity for all groups, with the exception of SPCL/cell constructs cultured with $\alpha$-amylase and lipase. There was no apparent positive effect of adding enzymes to culture media on ALP activity implying that the influence of enzymes predominantly affected the later osteoblastic differentiation, as characterized by mineralization (Fig. 6), more than the early osteoblastic differentiation, as characterized by ALP activity.

\section{Calcium deposition measurement}

The calcium content in scaffolds is an indication of the production of mineralized matrix and a marker of the late-stage osteoblastic differentiation of cells. ${ }^{11,14}$ Even in static cultures, there was a significant increase in the mineralization of SPCL/cell constructs in the presence of either enzyme between day 8 and 16. It has been previously reported that lipase enhanced osteogenic differentiation of MSCs under static conditions. ${ }^{8}$ A similar increase in calcium deposition under static conditions with $\alpha$-amylase was observed in this study as well, although a combination of the enzymes failed to produce a similar increase in calcium deposition. The calcium data were corroborated by SEM images where it is possible to see the cross sections of the constructs and the enhanced distribution of MSCs and ECM throughout the constructs when flow perfusion bioreactors were used (Fig. 3 ). In flow perfusion conditions, the mineralized matrix content of all groups (with or without enzyme supplementation) cultured for 16 days was greatly increased over those cultured in static conditions (Fig. 6). SPCL/cell constructs cultured with lipase under flow perfusion conditions showed increased calcium content (1271 $\pm 32 \mu \mathrm{g} /$ scaffold $)$ when compared with SPCL cultured without enzymes (907 $\pm 124 \mu \mathrm{g} / \mathrm{scaffold})$. In addition, SPCL/cell constructs cultured in flow perfusion bioreactors with both enzymes $(\alpha$ amylase and lipase) showed significantly greater calcium deposition at 8 days when compared with other groups.
The calcium data were further corroborated by SEM images, where cross sections of the constructs showed deeper and more extensive distribution of mineralized ECM throughout the constructs when flow perfusion bioreactors were used (Fig. 3).

One of the objectives of this study was to examine the efficacy of the enzymes in inducing osteogenic differentiation. The literature indicates that besides being responsible for poly( $\varepsilon$-caprolactone) degradation, lipase plays an important role in osteoblastic differentiation of rat bone marrow stromal cells when added to culture media. ${ }^{8}$ Under flow perfusion conditions and in the presence of lipase, SPCL/ cell constructs cultured for 16 days in this study showed the highest amount of calcium (1271 $\pm 32 \mu \mathrm{g} / \mathrm{scaffold})$. However, the calcium content of SPCL/cell constructs cultured under flow perfusion condition with culture medium supplemented with both enzymes ( $\alpha$-amylase and lipase) was $737 \pm 25 \mu \mathrm{g} /$ scaffold, only slightly higher than that obtained with culture medium supplemented with $\alpha$-amylase. This indicates that the presence of $\alpha$-amylase does not enhance the deposition of calcium and therefore the osteogenic differentiation of MSCs. Furthermore, $\alpha$-amylase does not appear to improve the cellularity of MSCs on the SPCL constructs. Considering these results, it can be hypothesized that the lower calcium amount could be related to the lower cell number obtained with cellular scaffold constructs treated with $\alpha$-amylase. The decrease in cell number observed with $\alpha$-amylase could be attributed to the loss of surface area of SPCL fiber scaffolds, due to the degradation of starch present within the scaffold in the presence of $\alpha$-amylase. It has been previously shown that SPCL scaffolds, which are a blend of 30\% starch and 70\% PCL, undergo significant weight loss in the presence of $\alpha$-amylase. ${ }^{8}$ A weight loss of $\sim 25 \%$ was observed between day 7 and 14 in $\alpha$-amylase, which was significantly greater than the weight loss observed in the presence of lipase alone. This study indicated that the weight loss in the presence of $\alpha$-amylase was mainly due to the partial degradation and release of starch present in the SPCL scaffolds. Moreover, when SPCL/cell constructs were cultured under flow and in the presence of $\alpha$-amylase, the number of cells was lower when compared with the other groups. For this condition, the calcium data reflected a lower degree of mineralization. One possible explanation could be related to the degradation of starch by $\alpha$-amylase after 16 days of culture under flow conditions. Previous degradation studies with $\alpha$-amylase showed a pronounced weight loss of $\sim 25 \%$ after 3 days which increased slightly to $30 \%$ after 30 days. $^{8}$ Since SPCL is a blend of $30 \%$ starch and $70 \%$ poly( $\varepsilon$-caprolactone), this weight loss might be related with the degradation of starch. Based on this hypothesis, $\alpha$-amylase does not have a negative effect on osteogenic differentiation of MSCs, but the differences observed in the data might be related to the degradation of the starch component of the fibers.

\section{von Kossa staining and tetracycline fluorescence}

Mineral deposition is considered to be a marker of full maturation of the osteoblast phenotype in differentiating bone 

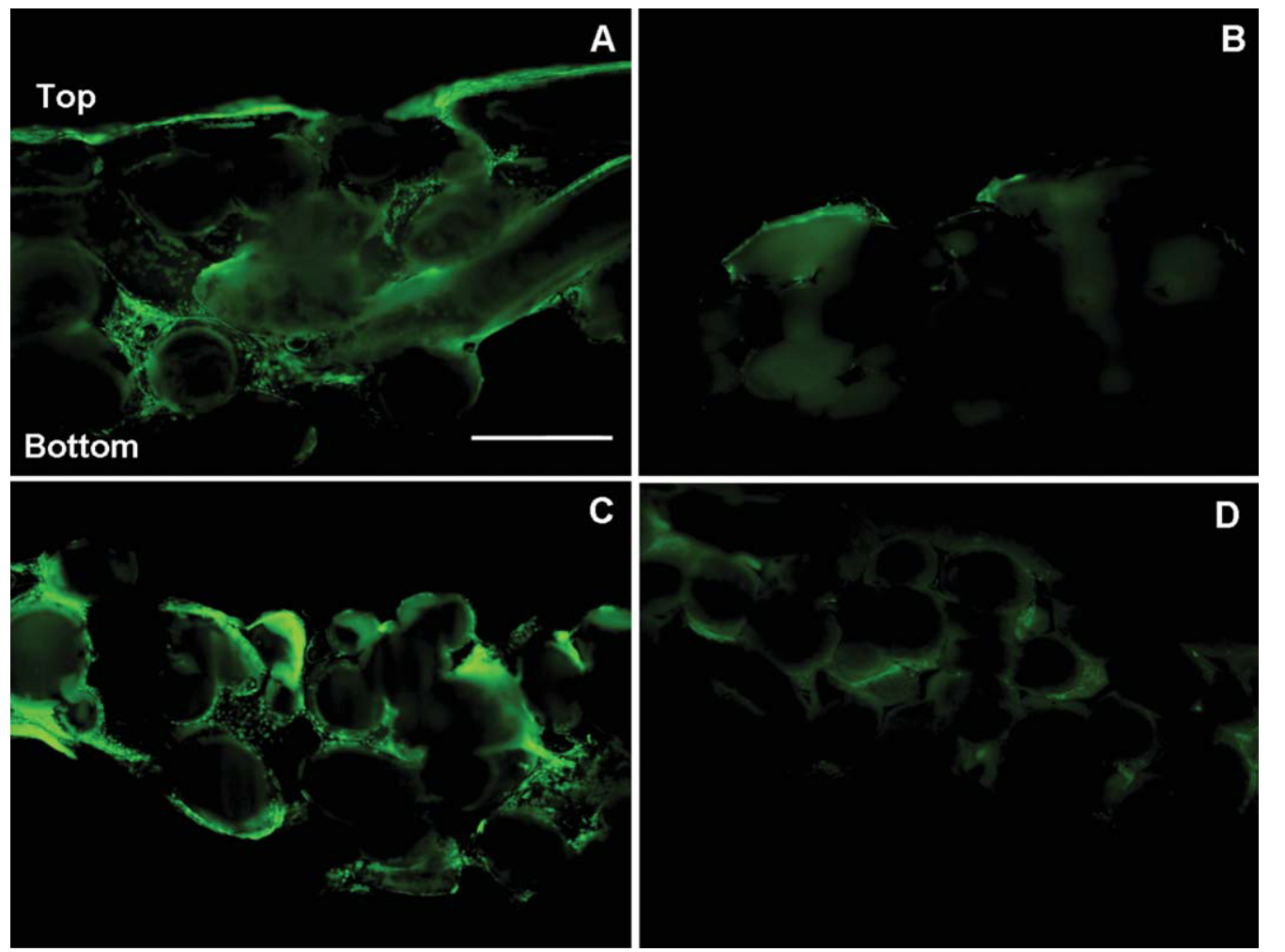

FIGURE 7. Sections of SPCL fiber meshes cultured without enzymes (A), with $\alpha$-amylase (B), with lipase (C), or with $\alpha$-amylase and lipase (D) for 16 days observed under fluorescent light, showing the tetracycline labeling of mineral in flow perfusion culture conditions. All images were obtained using a $\times 4$ APO objective. The scale bar is $500 \mu \mathrm{m}$ and applies to all images. [Color figure can be viewed in the online issue, which is available at www.interscience.wiley.com.]

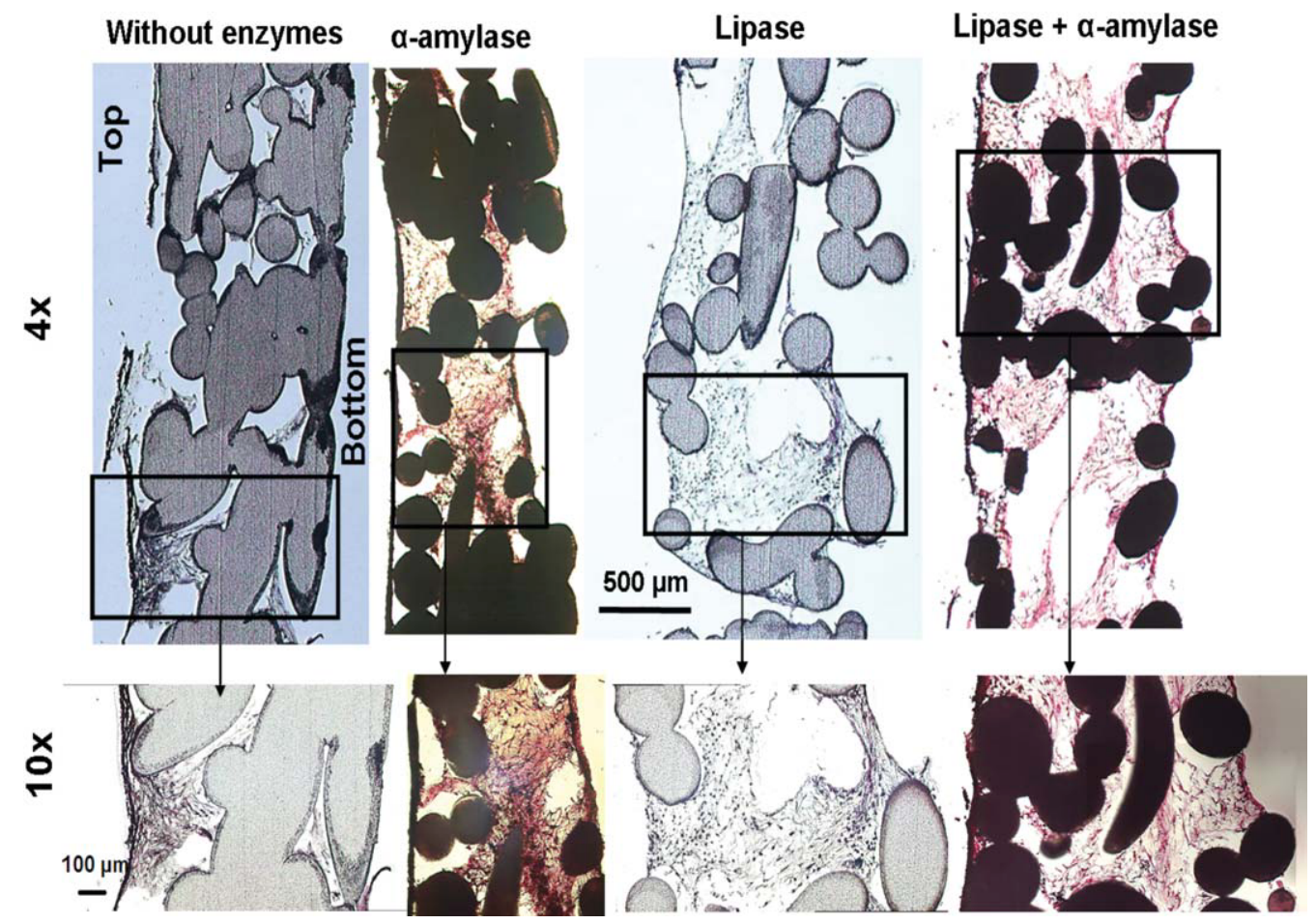

FIGURE 8. von Kossa stained histological sections of SPCL fiber mesh scaffolds cultured in vitro without enzymes, with $\alpha$-amylase, with lipase, or with $\alpha$-amylase and lipase for 16 days at different magnifications under flow perfusion conditions. [Color figure can be viewed in the online issue, which is available at www.interscience.wiley.com.] 
marrow stromal cells. The von Kossa stained sections of all groups cultured for 16 days demonstrated that flow perfusion had a positive effect in the deposition of extracellular matrix, in agreement with the previous results. ${ }^{2}$

Tetracycline is a fluorochrome-labeling agent for bone tissues. ${ }^{23}$ Tetracycline accumulates at bone forming sites and fluoresces brightly when activated with fluorescent light. Figure 7 indicates numerous regions in the interior of the scaffolds from all groups cultured under flow conditions where mineral deposition has occurred after 16 days in culture. In contrast, minimal tetracycline fluorescence appeared in scaffolds cultured under static conditions (data not shown). Furthermore, tetracycline fluorescence shows that mineral was more evenly distributed within the scaffold when the constructs were cultured in flow conditions, whereas constructs cultured statically had fluorescence limited to the outer edges of the scaffold. As noted previously, Figure $7(A, C)$ shows an enhanced distribution and greater amount of mineral deposition throughout the SPCL/cell constructs cultured without enzymes or with lipase, when compared with SPCL/cell constructs cultured with $\alpha$-amylase or both enzymes together.

SEM imaging, von Kossa staining, and tetracycline images showed that the mesh pores of the flow perfusion samples were almost completely filled with matrix after 16 days when SPCL/cell constructs were cultured with osteogenic medium supplemented with lipase. These results were also corroborated by the calcium data, presented above, where the greatest content of calcium was measured when lipase was present. Osteogenic culture medium supplemented with lipase did not only stimulate enhancement of mineralized matrix deposition (Fig. 6) but also generated mineralized extracellular matrix that was distributed throughout the porosity of the scaffolds [Figs. 7(C) and 8]. Lipase is a molecule previously shown to be capable of directing osteoblastic differentiation of rat MSCs cultured statically. ${ }^{8}$ This work corroborates these previous findings and further shows that lipase promotes the osteoblastic differentiation of rat MSCs, especially when coupled with flow perfusion culture.

\section{CONCLUSIONS}

This work demonstrates that osteogenic media supplemented with $\alpha$-amylase, or with $\alpha$-amylase and lipase together, and cultured in flow perfusion bioreactors did not enhance osteoblastic differentiation of rat marrow stromal cells compared with SPCL/cell constructs without enzymes. However, it was observed that SPCL fiber mesh scaffold/ MSC constructs cultured with osteogenic medium supplemented with lipase under flow perfusion were more mineralized than the other groups examined, which indicates latestage osteoblastic differentiation of MSCs. This study demonstrates that lipase and flow perfusion conditions act as effective osteogenic stimuli in the differentiation of rat marrow stromal cells, also promoting the production of mineralized extracellular matrix. This strategy of using scaffolds that are enzymatically degraded by enzymes naturally present in the human blood serum, together with demonstrated improvement of osteoblastic differentiation of MSCs by lipase under flow perfusion conditions shows promising results for bone tissue engineering applications.

\section{ACKNOWLEDGMENTS}

The authors acknowledge Ana R. Costa-Pinto for her help on discussion of the obtained data.

\section{REFERENCES}

1. Hutmacher DW, Schantz JT, Lam CXF, Tam KC, Lim TC. State of the art and future directions of scaffold-based bone engineering from a biomaterials perspective. J Tissue Eng Regen Med 2007;1: 245-260.

2. Gomes ME, Sikavitsas VI, Behravesh E, Reis RL, Mikos AG. Effect of flow perfusion on the osteogenic differentiation of bone marrow stromal cells cultured on starch-based three-dimensional scaffolds. J Biomed Mater Res A 2003;67:87-95.

3. Gomes ME, Holtorf HL, Reis RL, Mikos AG. Influence of the porosity of starch-based fiber mesh scaffolds on the proliferation and osteogenic differentiation of bone marrow stromal cells cultured in a flow perfusion bioreactor. Tissue Eng 2006;12:801-809.

4. Azevedo HS, Gama FM, Reis RL. In vitro assessment of the enzymatic degradation of several starch based biomaterials. Biomacromolecules 2003;4:1703-1712.

5. Balmayor ER, Tuzlakoglu K, Marques AP, Azevedo HS, Reis RL. A novel enzymatically-mediated drug delivery carrier for bone tissue engineering applications: Combining biodegradable starch-based microparticles and differentiation agents. J Mater Sci Mater Med 2008;19:1617-1623.

6. Gomes ME, Azevedo HS, Moreira AR, Ella V, Kellomaki M, Reis RL. Starch-poly(epsilon-caprolactone) and starch-poly(lactic acid) fibre-mesh scaffolds for bone tissue engineering applications: Structure, mechanical properties and degradation behaviour. J Tissue Eng Regen Med 2008;2:243-252.

7. Martins AM, Santos MI, Azevedo HS, Malafaya PB, Reis RL. Natural origin scaffolds with in situ pore forming capability for bone tissue engineering applications. Acta Biomater 2008;4:1637-1645.

8. Martins AM, Pham OP, Malafaya PB, Sousa RA, Gomes ME, Raphael RM, Kasper FK, Reis RL, Mikos AG. The role of lipase and alpha-amylase in the degradation of starch/poly(epsilon-caprolactone) fiber meshes and the osteogenic differentiation of cultured marrow stromal cells. Tissue Eng Part A 2009;15:295-305.

9. Mochizuki M, Hirano M, Kanmuri Y, Kudo K, Tokiwa Y. Hydrolysis of polycaprolactone fibers by lipase-Effects of draw ratio on enzymatic degradation. J Appl Polym Sci 1995;55:289-296.

10. Zeng J, Chen X, Liang $Q$, Xu X, Jing X. Enzymatic degradation of poly(L-lactide) and poly(epsilon-caprolactone) electrospun fibers. Macromol Biosci 2004;4:1118-1125.

11. Owen TA, Aronow M, Shalhoub V, Barone LM, Wilming L, Tassinari MS, Kennedy MB, Pockwinse S, Lian JB, Stein GS. Progressive development of the rat osteoblast phenotype in vitro: Reciprocal relationships in expression of genes associated with osteoblast proliferation and differentiation during formation of the bone extracellular matrix. J Cell Physiol 1990;143:420-430.

12. Beck GR, Zerler B, Moran E. Phosphate is a specific signal for induction of osteopontin gene expression. Proc Natl Acad Sci USA 2000;97:8352-8357.

13. Bancroft GN, Sikavitsas VI, Van Den Dolder J, Sheffield TL, Ambrose CG, Jansen JA, Mikos AG. Fluid flow increases mineralized matrix deposition in 3D perfusion culture of marrow stromal osteoblasts in a dose-dependent manner. Proc Natl Acad Sci USA 2002;99:12600-12605.

14. Sikavitsas VI, Bancroft GN, Holtorf HL, Jansen JA, Mikos AG. Mineralized matrix deposition by marrow stromal osteoblasts in $3 \mathrm{D}$ perfusion culture increases with increasing fluid shear forces. Proc Natl Acad Sci USA 2003;100:14683-14688.

15. Maniatopoulos $\mathrm{C}$, Sodek J, Melcher AH. Bone formation in vitro by stromal cells obtained from bone marrow of young adult rats. Cell Tissue Res 1988;254:317-330.

16. Junge W, Troge B, Klein G, Poppe W, Gerber M. Evaluation of a new assay for pancreatic amylase: Performance characteristics 
and estimation of reference intervals. Clin Biochem 1989;22: 109-114.

17. Chawla JS, Amiji MM. Biodegradable poly(epsilon-caprolactone) nanoparticles for tumor-targeted delivery of tamoxifen. Int J Pharm 2002;249:127-138.

18. Bancroft GN, Sikavitsas VI, Mikos AG. Design of a flow perfusion bioreactor system for bone tissue-engineering applications. Tissue Eng 2003;9:549-554.

19. Datta N, Holtorf HL, Sikavitsas VI, Jansen JA, Mikos AG. Effect of bone extracellular matrix synthesized in vitro on the osteoblastic differentiation of marrow stromal cells. Biomaterials 2005;26:971-977.

20. Sikavitsas VI, Bancroft GN, Lemoine JJ, Liebschner MA, Dauner M, Mikos AG. Flow perfusion enhances the calcified matrix depo- sition of marrow stromal cells in biodegradable nonwoven fiber mesh scaffolds. Ann Biomed Eng 2005;33:63-70.

21. Pham QP, Sharma U, Mikos AG. Electrospun poly(epsilon-caprolactone) microfiber and multilayer nanofiber/microfiber scaffolds: Characterization of scaffolds and measurement of cellular infiltration. Biomacromolecules 2006;7:2796-2805.

22. Gomes ME, Bossano CM, Johnston CM, Reis RL, Mikos AG. In vitro localization of bone growth factors in constructs of biodegradable scaffolds seeded with marrow stromal cells and cultured in a flow perfusion bioreactor. Tissue Eng 2006;12:177-188.

23. Frost HM, Vilanueva AR, Jett S, Eyring E. Tetracycline-based analysis of bone remodelling in osteopetrosis. Clin Orthop Relat Res 1969;65:203-217. 